patients with intermediate probability of $\mathrm{PH}$, one patient had intermittent palpitation and chest pain, while others were asymptomatic including one patient with $\mathrm{PAH}$ based on RHC. The most prevalent auto-antibodies among patients with intermediate and high probability of $\mathrm{PH}$ were anti-Ro (8 patients), anti-nuclear antibodies (7 patients) and anti-dsDNA (5 patients).

Conclusion: We found $16.6 \%$ patients with SLE who had intermediate and high probability of $\mathrm{PH}$, based on 2015 ESC echocardiography criteria for $\mathrm{PH}$. All except one patient had symptoms suggestive of $\mathrm{PH}$ at the time of study. $\mathrm{RHC}$ performed subsequently on two patients with high $\mathrm{PH}$ probability confirmed PAH.

References:

[1] Galie N, Humbert M, Vachiery JL, et al. European Heart Journal, 2016; 37(1):67-119

Acknowledgments : We are thankful to Mrs Maisarah, our dedicated echocardiography technician.

Disclosure of Interests: Hazlyna Baharuddin Speakers bureau: Sanofi, J\&J, Nur Farhana Abdul Manaf: None declared, Zaliha Ismail: None declared, Khairul Shafiq Ibrahim: None declared, Mollyza Mohd Zain: None declared, Shereen Suyin Ch'ng Speakers bureau: Novartis, Pfizer, GSK

DOI: 10.1136/annrheumdis-2020-eular.6401

\section{SAT0199 PARTICULARITIES OF SJÖGREN SYNDROME IN ELDERLY PATIENTS}

I. Naceur ${ }^{1}$, R. Abida ${ }^{1}$, T. Ben Salem ${ }^{1}$, F. Said ${ }^{1}$, M. Khanfir ${ }^{1}$, I. Ben Ghorbel ${ }^{1}$, M. Lamloum ${ }^{1}$, M. H. Houman ${ }^{1} .{ }^{1}$ Faculty of Medicine, Tunis-El Manar University, Inetrnal Medicine, Rabta university Hospital, Tunis, Tunisia

Background: Sjögren syndrome (SS) is a systemic autoimmune disease mainly described in females at a peak incidence age of 50 . It was suggested that elderly onset of disease has particular clinical and biological phenotype.

Objectives: The aim of our study is to determine the particularities of SS in elderly patients.

Methods: Data of 332 patient fulfilling the American European Consensus Group criteria for Sjögren's syndrome over a period time of 18 years were studied. Clinical and biological features of elderly patients (G1) were described and compared to those of patients aged below 65 years old (G2) using the X2 and Fisher test.

Results: A total of 35 elderly were retained: 33 females and 2 males. The mean age of disease onset was $68.8 \pm 4.4$ years. The average delay (from first sign of the disease to diagnosis) was 1.27 years. The mean age at diagnosis was 70.3 \pm 4.7 years. Xerostomia was described by 33 patients $(94.3 \%)$. Focus score in the minor labial salivary glands pathology was $\geq 1$ in 32 patients $(91.4 \%)$. Two patients had abnormalities in parotid scintigraphy. Xeropthalmia was described by 32 elderly patients (91.4\%). Schirmer test was abnormal in 20 cases $(57.1 \%)$ and Break Up Time test was altered in 20 cases $(57.1 \%)$. Arthralgia was the most frequent extra-glandular manifestation reported in $74.3 \%$ of patients. Fatigue was noted in 12 patients. The other systemic manifestations were: interstitial lung disease $(n=13)$, peripheral neuropathy $(n=7)$, central nervous system involvement $(n=5)$, Raynaud's phenomenon $(n=4)$, myositis $(n=2)$ and renal tubulopathy $(n=2)$. Laboratory findings showed hyperglobulinemia $(n=19)$ and lymphopenia $(n=15)$. Antinuclear antibodies were positive in 25 patients $(71.4 \%)$ with positive anti-SSA antibodies $(n=14)$ and positive anti-SSB antibodies $(n=7)$. SS was primary in 25 patients. Ten patients had one or more associated autoimmune diseases: cryoglobulinemia $(n=4)$, systemic scleroderma $(n=3)$, systemic lupus erythematosus $(n=2)$, rheumatoid arthritis $(n=2)$ and autoimmune hepatopathy $(n=2)$.

Systemic treatments involved corticosteroids for 15 patients, antimalarial agents for 12 patients, nonsteroidal anti-inflammatory drugs for three patients and immunosuppressant agents for nine patients. One patient developed lymphoma.

Comparative analysis showed that SS diagnosis was made earlier in elderly with an average delay of 1.27 years in $G 1$ vs 3 years in $G 2(p=0.02)$. Fatigue was more frequent in elderly $(63.2 \%$ vs $23.8 \%) p<0.01$. Positivity of anti-SSA was also more frequent in elderly $(64.9 \%$ vs $46.7 \% ; p=0.04)$. Anti-malarial agents were less prescribed in elderly ( $36.4 \%$ vs $55.3 \% ; p=0.03)$. There was no significant differences between the two groups concerning the other clinical features, laboratory findings, treatment and outcomes.

Conclusion: Regardless of the statistical findings in our study and in the literature, treatment and follow-up of elderly patients with SS must obey to closer attention considering their vulnerability and the complexity of their management.

Disclosure of Interests: None declared

DOI: 10.1136/annrheumdis-2020-eular.6199

\section{\begin{tabular}{|l|l}
\hline SAT0200 & RISK FACTORS FOR ADVERSE PREGNANCY
\end{tabular} OUTCOMES IN SYSTEMIC LUPUS ERYTHEMATOSUS PATIENTS}

C. Cetin ${ }^{1}$, T. Saraç-Sivrikoz ${ }^{2}$, M. Ateş-Tıkız², E. S. Torun ${ }^{1}$, A. Ersoy ${ }^{1}$,

Y. Yalçınkaya ${ }^{1}$, A. Gul ${ }^{1}$, M. Inanc ${ }^{1}$, M. L. Ocall ${ }^{1}$ İ. Kalelioğlu ${ }^{2}$, B. Artim-

Esen ${ }^{1} .{ }^{1}$ Istanbul Faculty of Medicine, Rheumatology, İstanbul, Turkey; ${ }^{2}$ Istanbul

Faculty of Medicine, Obstetrics and Gynecology, İstanbul, Turkey

Background: Pregnancies of patients with systemic lupus erythematosus (SLE) can be risky both for the mother and the fetus because of disease activity and pregnancy complications. ${ }^{1}$

Objectives: In this study, we evaluated the risk factors related to adverse pregnancy outcomes (APO) in our pregnant SLE cohort who were followed up by both Rheumatology and Obstetrics and Gynecology departments at our university. Methods: 168 pregnancy data were analyzed from 136 patients who fulfilled ACR classification criteria for SLE. The course of pregnancies were monitored and fetal/neonatal outcomes were recorded. Unexplained fetal death after 12 weeks of gestation, neonatal death, preterm birth due to preeclampsia, eclampsia or HELLP and birth of small for gestational age (SGA) infant were defined as APO. Cumulative clinical, laboratory and serological findings, disease activity (SLEDAI-2K) and damage (SLICC/ACR), and conventional risk factors were compared between $\mathrm{APO}(+)$ and $\mathrm{APO}(-)$ groups.

Results: The comparison of demographics, conventional risk factors and disease characteristics in $\mathrm{APO}(+)$ and $\mathrm{APO}(-)$ groups are summarized in Table- 1 In $\mathrm{APO}(+)$ pregnancies, the duration of disease was longer $(\mathrm{p}<0.05)$ and the frequency of chronic hypertension was higher $(p<0.05)$ compared to APO(-) pregnancies. Renal and neuropsychiatric (NP) involvement, thrombocytopenia, antiphospholipid syndrome (APS), lupus anticoagulant and anti-cardiolipin IgM positivity were significantly higher in $\mathrm{APO}(+)$ group. Mean SLEDAI-2K scores of three trimesters and postpartum 6 months were higher in $\mathrm{APO}(+)$ patients compared to APO(-) patients $(2.2 \pm 3.6$ vs $1.2 \pm 2.04, p<0.05 ; 4.9 \pm 6.03$ vs 2.7 $\pm 5.01, p=0.02$, respectively). Percentage of patients with damage at the beginning of pregnancy and the mean SLICC damage score were significantly higher in $\mathrm{APO}(+)$ group compared to $\mathrm{APO}(-)$ group $(1.8 \pm 2.1$ vs $0.8 \pm 1.3, \mathrm{p}<0.05)$. In $\mathrm{APO}(+)$ group, damage was significantly higher in neuropsychiatric, renal and cardiovascular and locomotor systems $(p<0.05)$.

Conclusion: Although an important proportion of SLE pregnancies result in live birth, active disease, especially renal and NP involvement, and presence of damage at the beginning of pregnancy increase the risk of maternal and fetal complications. Furthermore, the presence of APS or antiphospholipid antibody positivity are important risk factors for obstetric complications. In conclusion, pregnancy should be allowed after controlling the disease activity and patients should be closely monitored in coordination with Obstetrics and Gynecology clinics. In case of presence of damage, both the patient and the physician should be aware of a possible adverse pregnancy outcome.

References:

[1] Ann Intern Med. 2015 August 4; 163(3): 153-163. doi:10.7326/M14-2235.

Table 1. Demographic data of APO (+) and APO (-) groups, comparison of conventional risk factors, cumulative clinical, serological and laboratory features

\begin{tabular}{|c|c|c|c|}
\hline & $\begin{array}{c}\operatorname{APO}(-) \\
(n=111)\end{array}$ & $\begin{array}{r}\operatorname{APO}(+) \\
\quad(n=57)\end{array}$ & $\mathrm{p}$ \\
\hline Age & $35.1 \pm 6.7$ & $34.9 \pm 5.9$ & NS \\
\hline Age at conception & $30.6 \pm 5.6$ & $28.9 \pm 4.2$ & NS \\
\hline Disease duration (months) & $141.6 \pm 70$ & $166.9 \pm 87.9$ & $<0.05$ \\
\hline Chronic hypertension, n (\%) & $6(7)$ & $11(19.6)$ & $<0.05$ \\
\hline Photosensitivity, n (\%) & $86(77.5)$ & $43(75.4)$ & NS \\
\hline Malar rash, n (\%) & $66(59.5)$ & $38(66.7)$ & NS \\
\hline Oral ulcer, n (\%) & $11(9,9)$ & $6(10.5)$ & NS \\
\hline Arthritis, $\mathrm{n}(\%)$ & $77(59.4)$ & $42(73.7)$ & NS \\
\hline Serositis, n (\%) & $17(15.3)$ & $13(22.8)$ & NS \\
\hline Renal, n (\%) & $39(35.1)$ & $30(52.6)$ & $<0.05$ \\
\hline Hematologic, n (\%) & $78(70.3)$ & $40(70.2)$ & NS \\
\hline Thrombocytopenia, n (\%) & 37 (33.3) & $30(52.6)$ & $<0.05$ \\
\hline AIHA, n (\%) & $16(14.4)$ & $14(24.6)$ & NS \\
\hline Neurologic, n (\%) & $7(6.3)$ & $9(15.8)$ & $<0.05$ \\
\hline Anti-cardiolipin IgG, n(\%) & $28(25.2)$ & $18(32.1)$ & NS \\
\hline Anti-cardiolipin IgM, n (\%) & $18(16.2)$ & $18(32.1)$ & $<0.05$ \\
\hline Lupus anticoagulant, $\mathrm{n}(\%)$ & $26(23.4)$ & $28(49.1)$ & $<0.001$ \\
\hline Antiphospholipid syndrome, $n(\%)$ & $28(25.2)$ & $30(52.6)$ & $<0.001$ \\
\hline
\end{tabular}

(NS=not significant, $\mathrm{APO}=$ adverse pregnancy outcome, $\mathrm{AlHA}=$ autoimmune hemolytic anemia)

Disclosure of Interests: : None declared

DOI: 10.1136/annrheumdis-2020-eular.3172 